\title{
Avaliação e comparação microestrutural e das propriedades mecânicas entre um aço carbono e um aço microligado para aplicação em rodas ferroviárias
}

\section{Evaluation and comparison of microstructural and mechanical properties between carbon steel and microalloyed steel for railway wheel application}

Luiz Gustavo de Oliveira ${ }^{1}$, Cristina Sayuri Fukugauchi ${ }^{1}$, Antonio dos Reis de Faria Neto ${ }^{2}$, Valdir Alves Guimarães ${ }^{2}$

\footnotetext{
${ }^{1}$ Instituto Federal de São Paulo (IFSP) - Campus de São José dos Campos, CEP: 12223-201, São José dos Campos, SP, Brasil.

${ }^{2}$ Universidade Estadual Paulista (UNESP) - Campus de Guaratinguetá, CEP: 12516-410, Guaratinguetá, SP, Brasil. e-mail: lgustavo@ifsp.edu.br, cristinafukugauchi@ifsp.edu.br, antonio.fariant@gmail.com, valdir@ feg.unesp.br
}

\section{RESUMO}

O setor ferroviário sempre tem estado em busca de um aumento do rendimento de seus produtos envolvidos no transporte de cargas e passageiros. Uma das formas de aumentar a eficiência deste tipo de transporte se baseia no aumento da velocidade dos trens e das cargas transportadas por eixo, o que torna as ferrovias mais competitivas. No entanto, estas soluções geram elevadas tensões nas rodas ferroviárias aumentando assim a possibilidade de ocorrerem falhas por fadiga nas mesmas. Neste contexto, o objetivo deste trabalho é avaliar as propriedades mecânicas, incluindo fadiga, e as características microestruturais dos materiais utilizados na fabricação de rodas ferroviárias. Foram avaliados três materiais diferentes (Aço carbono - amostra fundida e forjada; Aço Microligado - amostra forjada) utilizados neste segmento através de ensaio microestrutural, tração, tenacidade à fratura e fadiga, sendo uma roda fabricada por forjamento e com aço classe "C $\mathrm{C}$ " $(0,7 \%$ C), uma fabricada por fundição com o mesmo material e outra roda forjada produzida com o aço classe " $\mathrm{C}$ " desgaseificado à vácuo e microligado com nióbio e molibdênio. Os resultados dos ensaios indicam que a roda forjada e microligada apresentou valores superiores das propriedades mecânicas quando comparado aos demais materiais estudados. Além disso, o processo de fabricação por forjamento apresentou melhores resultados quando comparado ao processo de fundição.

Palavras-chave: Aço Microligado. Forjamento. Fundição. Fadiga. Tenacidade à Fratura.

\section{ABSTRACT}

The railway sector has always been looking for an increase in the yield of its products involved in the transportation of cargo and passengers. One of the ways to increase the efficiency of this type of transport is based on increasing the speed of the trains and the loads transported per axle, which makes the railways more competitive. However, these solutions generate high stresses on the railway wheels, thus increasing the possibility of failure due to fatigue in them. In this context, the objective of this work is to evaluate the mechanical properties, including fatigue, and the microstructural characteristics of the materials used in the manufacture of railway wheels. Three different materials were evaluated (Carbon steel - cast and forged sample; Microalloyed steel - Forged sample) used in this segment through microstructural testing, traction, fracture toughness and fatigue, a wheel manufactured by forging and with class steel. " $\mathrm{C}$ " $(0.7 \% \mathrm{C})$, one manufactured by casting with the same material and another forged wheel produced with vacuum-degassed class " $C$ " steel and micro-bonded with niobium and molybdenum. The results of the tests indicate that the forged and microalloyed wheel presented superior values of the mechanical properties when compared to the other studied materials. In addition, the forging manufacturing process showed better results when compared to the casting 
process.

Keywords: Micro Alloy Steel. Forging. Foundry. Fatigue. Fracture toughness.

\section{INTRODUÇÃO}

O transporte ferroviário, seja de pessoas ou de cargas, exerce uma importante função na malha viária de países desenvolvidos e em desenvolvimento [1,2]. Em 2018 foram registrados mais de 1800 acidentes com trens nos Estados Unidos [3], sendo que cerca de 70\% foram devido ao descarrilamento. Neste âmbito, as rodas ferroviárias se destacam como um importante componente de segurança e um dos mais críticos devido as solicitações sofridas. Este componente deve ser bem projetado para suportar cargas devido ao atrito com o trilho, solicitações térmicas e esforços mecânicos [2].

Além do mencionado, o desenvolvimento do setor ferroviário nos últimos anos e a necessidade do aumento do rendimento de seus produtos e componentes têm exigido cada vez mais velocidades, cargas e tamanho das composições no transporte [4,5]. Em consequência, tem aumentado o fenômeno de falha por fadiga de componentes durante a operação de transporte dos trens [6], requerendo, assim, maior resistência dos materiais das rodas para suportar estes esforços.

O estudo da falha pelo fenômeno da fadiga é primordial para qualquer projeto de componente mecânico ou estrutura submetida a cargas dinâmicas, sendo esta o tipo de falha mais comum e imprevisível [1]. Ganha ainda mais importância quando se trata de um componente vital como as rodas dos trens, que qualquer problema pode levar a graves consequências [2], por exemplo, a sobrecarga nos eixos [7], e em último caso a falha e o descarrilamento.

Atualmente, as rodas são fabricadas de aço com médio e alto teor de carbono na faixa de 0,45 a $0,77 \%$ de $\mathrm{C}$ em peso, cuja estrutura é composta por perlita e ferrita proeutetóide. A norma americana AAR M-107 (2011) [8] divide os materiais em classes de acordo com o tipo de aplicação, e as rodas fabricadas com materiais da classe C possuem 0,72\% de carbono, Dureza Brinell média de 310, Limite de Escoamento de 710 $\mathrm{MPa}$, Tenacidade (Impacto) de 7,1 J e Tenacidade a fratura de $32 \mathrm{MPa} \cdot \mathrm{m}^{1 / 2}$.

As propriedades dos materiais com os quais as rodas são fabricadas dependem da microestrutura. A perlita, composta de ferrita eutetóide e cementita, determina o grau de resistência e ductilidade do material. Essas propriedades são uma função do espaçamento entre as lamelas das fases, da fração volumétrica de ferrita proeutetóide e do tamanho da colônia de perlita $[9,10]$. Como as propriedades são uma função da microestrutura final do material, pode-se conseguir alterá-las indiretamente, modificando a microestrutura através do processamento ou com adição de elementos de liga.

Neste contexto, o presente trabalho tem o objetivo de avaliar as propriedades mecânicas, incluindo fadiga, e as características microestruturais dos materiais utilizados na fabricação de rodas ferroviárias. Foram analisadas amostras de rodas produzidas por dois diferentes processos: forjamento e fundição, além de se avaliar uma terceira amostra de um aço forjado microligado ao Nióbio e Molibdênio desgaseificado à vácuo.

\section{MATERIAIS E MÉTODOS}

Os materiais utilizados neste trabalho foram fornecidos pela empresa MWL Brasil em forma de rodas utilizadas nos trens, conforme Figura 1. As rodas foram fabricadas e cedidas para os ensaios, sendo portanto, produtos não utilizados. Foram utilizados três materiais distintos provenientes de três rodas de vagão com diâmetro externo de 33", sendo denominada pela especificação como R-33. Duas rodas foram fabricadas pelo processo de forjamento, uma com o material Classe "C" e outra com o aço microligado, e uma roda foi fabricada com o aço Classe "C" pelo processo de fundição sob pressão em matriz de grafite.

Os corpos de prova foram retirados da região do aro da roda, por se tratar do local de maior solicitação mecânica,

Os ensaios realizados para a caracterização das rodas foram: composição química, ensaio de tração, microscopia óptica, tenacidade à fratura e fadiga. 


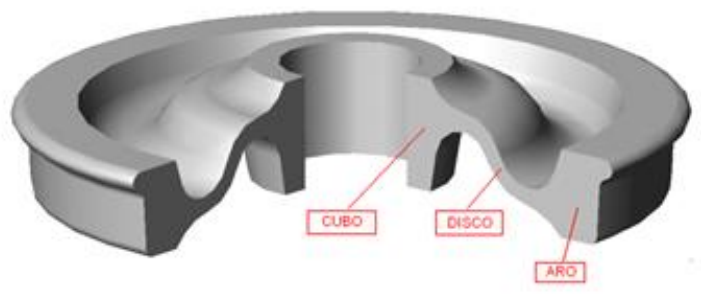

Figura 1: Nomenclatura das regiões de rodas ferroviárias.

\subsection{Composição química}

Para a análise das composições químicas dos materiais estudados foi utilizado um espectrômetro de emissão óptica, marca ARL, modelo 3460 e software WinOE com análise de 21 elementos, onde se obteve as porcentagens em peso dos principais elementos constituintes dos aços pesquisados.

\subsection{Ensaio de tração}

Os corpos de prova para o ensaio de tração cuja geometria está indicada na Figura 2(a), foram usinados segundo a norma ASTM E8/E8M - 16a [11]. Para cada material analisado foram preparados cinco corpos de prova retirados da região do aro da roda conforme ilustrado na Figura 2(b). Para os ensaios foi utilizada uma máquina de tração com capacidade para 40 toneladas, onde foram determinados os parâmetros de limite de resistência a tração $\left(\sigma_{\mathrm{T}}\right)$, limite de escoamento $\left(\sigma_{\mathrm{e}}\right)$, alongamento total (A) e redução de área (RA). Os ensaios foram realizados em temperatura ambiente.

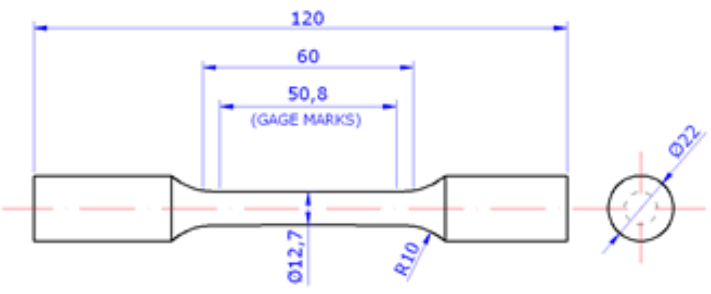

(a)

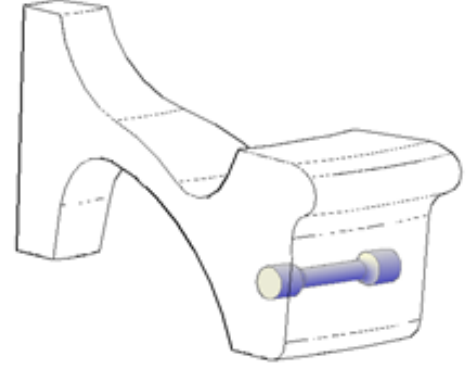

(b)

Figura 2: (a) Geometria do corpo de prova utilizado nos ensaios de tração (dimensões em milímetros); (b) Croqui da localização dos corpos de prova de tração na região do aro das rodas ferroviárias.

\subsection{Microscopia óptica}

As amostras utilizadas na análise microestrutural foram retiradas dos corpos de prova de tração após o ensaio dos mesmos. A região analisada foi a "cabeça" do corpo de prova. As técnicas utilizadas para a preparação metalográfica seguiram os processos normatizados pela ASTM E 3-11 (2017) [12] de seccionamento, embutimento (a quente, utilizando baquelite), lixamento (sequência granulométrica de 220, 320, 400, 600 e 1200) e polimento (pasta de diamante com granulometria de 3 e $1 \mu \mathrm{m}$ ). As amostras foram atacadas com o reagente Nital $2 \%$.

\subsection{Ensaio de tenacidade a fratura}

Foram realizados ensaios de tenacidade à fratura em temperatura ambiente, para os três materiais estudados neste trabalho. Os corpos de prova utilizados foram do tipo tração compacto $\mathrm{C}(\mathrm{T})$ com entalhe reto e foram confeccionados de acordo com o estabelecido pela norma ASTM E 399 (2019) [13] cuja geometria está esquematizada na Figura 3(a). O local de retirada das amostras é mostrado na Figura 3(b) e 3(c). 


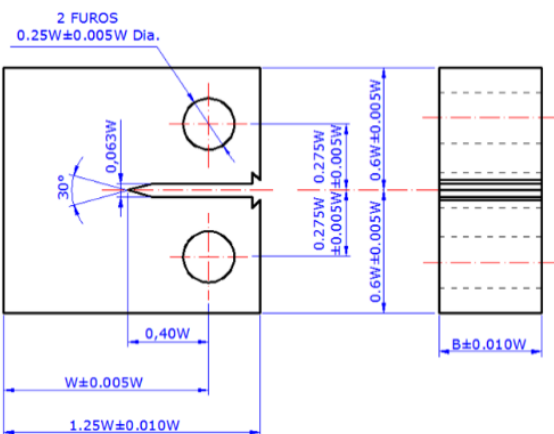

(a)

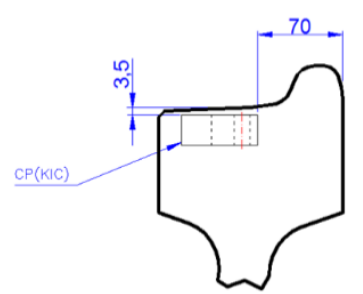

(b)

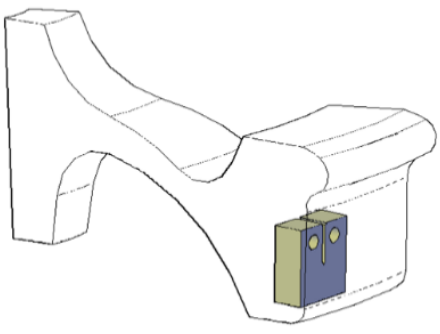

(c)

Figura 3: (a) Geometria do corpo de prova utilizado nos ensaios de tenacidade à fratura (dimensões em milímetros); (b) e (c) Localização e croqui dos corpos de prova de tenacidade à fratura na região do aro das rodas ferroviárias.

Para os ensaios foi utilizada uma máquina servo-hidráulica da marca INSTRON, modelo 8801, com capacidade para 10 toneladas e um extensômetro ("clip-on-gauge") INSTRON. Foram realizados quatro ensaios para cada condição estudada, sendo o valor de $\left(\mathrm{K}_{\mathrm{C}}\right)$ uma média aritmética dos resultados obtidos em cada ensaio, conforme recomendado pela norma ASTM E 399 (2019). Primeiramente, foram nucleadas as pré-trincas de fadiga com razão de carga de 0,1 e frequência de $10 \mathrm{~Hz}$. Neste trabalho, o tamanho da prétrinca de fadiga foi de $22,5 \mathrm{~mm}$ à $27,5 \mathrm{~mm}$, sendo em função da dimensão " $W$ " do corpo de prova. As cargas utilizadas durante o pré-trincamento são apresentadas na Tabela 1.

Após a obtenção da pré-trinca por fadiga, os corpos de prova foram submetidos a um carregamento monotônico, onde se obteve uma curva experimental da carga em função do deslocamento de abertura da trinca. A Figura 4 ilustra os tipos principais de curvas carga-deslocamento de abertura da trinca que normalmente são obtidas por este ensaio. A carga $P_{5}$ é obtida pela interseção da curva carga-deslocamento de abertura da ponta da trinca com uma reta com inclinação 5\% menor em relação a parte linear inicial da curva obtida pelo ensaio. Com a definição de $\mathrm{P}_{5}$ é possível definir a carga $\mathrm{P}_{\mathrm{Q}}$ que será utilizada para os cálculos de $\mathrm{K}_{\mathrm{IC}}$. A carga $\mathrm{P}_{\mathrm{Q}}$ é definida em função do tipo de curva obtida, $\mathrm{P}_{\mathrm{Q}}$ será igual a $\mathrm{P}_{5}$ para as curvas do tipo I, será igual a carga máxima antes da ocorrência do primeiro "pop-in" para o caso das curvas do tipo II, e igual a $\mathrm{P}_{\max }$ para curvas do tipo III. Uma vez definido o valor de $\mathrm{P}_{\mathrm{Q}}$, o valor de $\mathrm{K}_{\mathrm{Q}}$ é calculado com auxílio das equações (1) e (2) para os corpos de prova do tipo C(T).

Tabela 1: Cargas utilizadas durante o pré-trincamento dos corpos de prova.

\begin{tabular}{c|c|c}
\hline MATERIAL & $\begin{array}{c}\text { ESTÁGIO INICIAL DA PRÉ- } \\
\text { TRINCA (APROX. 80\% DE Kc }\end{array}$ & $\begin{array}{c}\text { ESTÁGIO FINAL DA PRÉ- } \\
\text { TRINCA (APROX. 60\% DE K }\end{array}$ \\
\hline Fundido; Forjado e Microligado & $18,5 \mathrm{kN}$ & $13,9 \mathrm{kN}$ \\
\hline
\end{tabular}




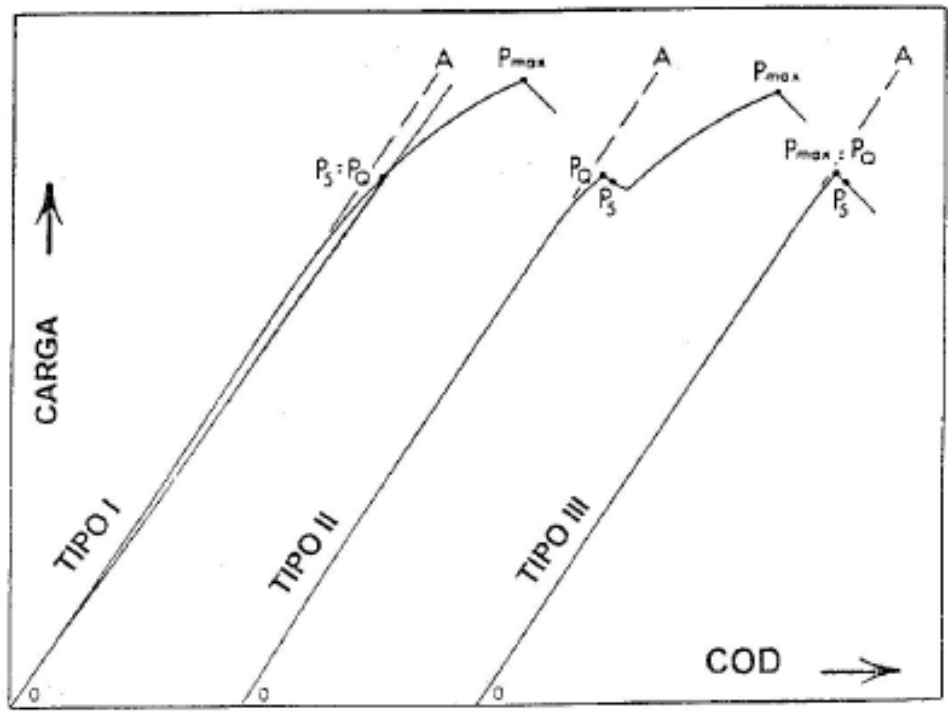

Figura 4: Principais tipos de curvas carga - deslocamento de abertura de trinca obtidas no ensaio $\mathrm{K}_{\mathrm{IC}}$ (adaptada da ASTM E399, 2019) [14].

$$
K_{Q}=\left(\frac{P_{Q}}{B W^{1 / 2}}\right) f(a / W)
$$

$$
f(a / W)=\frac{(2+a / W)\left[0,886+4,64(a / W)-13,32(a / W)^{2}+14,72(a / W)^{3}-5,6(a / W)^{4}\right]}{[1-(a / W)]^{3 / 2}}
$$

onde:

$\mathrm{K}_{\mathrm{Q}}$ - Fator de intensificação de tensão $[\mathrm{MPa} \sqrt{\mathrm{m}}]$;

$\mathrm{P}_{\mathrm{Q}}$ - Carga $[\mathrm{kN}]$;

B - Espessura do corpo de prova $[\mathrm{cm}]$;

a - Comprimento da trinca $[\mathrm{cm}]$;

$\mathrm{W}$ - Largura do corpo de prova [cm].

Nos trabalhos envolvendo materiais com aplicação ferroviária, é comum a nomenclatura $\mathrm{K}_{\mathrm{Q}}$ ser substituída por $\mathrm{K}_{\mathrm{C}}$. Neste trabalho será usada a nomenclatura $\mathrm{K}_{\mathrm{C}}$ para tratar dos resultados de Tenacidade à Fratura. Foi mantido nesta pesquisa o ensaio de $\mathrm{K}_{\mathrm{IC}}$, uma vez que outras técnicas de ensaio como CTOD e Integral J, não são comumente utilizadas nesse tipo de aplicação.

\subsection{Ensaio de fadiga axial}

Os ensaios de fadiga axial foram realizados em uma máquina servo-hidráulica da marca MTS, modelo FlexTest 40, com capacidade para 25 toneladas. O carregamento utilizado foi tipo senoidal de amplitude constante com controle de carga, sendo a frequência dos ensaios de $26 \mathrm{~Hz}$ e razão de carregamento $\mathrm{R}=0,1$, conduzidos na temperatura ambiente. Para o levantamento das curvas S-N foram utilizados 5 níveis de tensão para cada condição de material, e 3 corpos de prova para cada nível de tensão. O limite de resistência à fadiga foi definido em $10^{6}$ ciclos sem que ocorresse a fratura do corpo de prova.

Os corpos de prova utilizados para os ensaios foram confeccionados de acordo a norma ASTM E466 (2015) [15] cuja geometria está esquematizada na Figura 5(a). A retirada das amostras foi feita na região do aro da roda conforme Figura 5(b). 

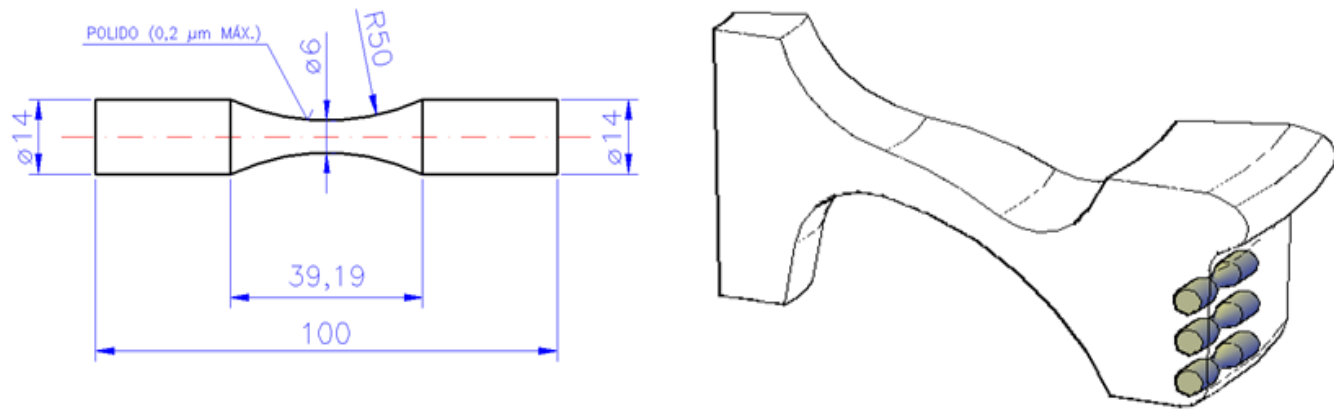

Figura 5: (a) Geometria do corpo de prova utilizado nos ensaios fadiga axial (dimensões em milímetros); (b) Croqui da localização dos corpos de prova de fadiga na região do aro das rodas ferroviárias.

\section{RESULTADOS E DISCUSSÃO}

Os resultados da composição química são mostrados na Tabela 2 e estão de acordo com os limites estabelecidos pela norma AAR M107 (2011) [16].

Observa-se, principalmente, a presença dos elementos $\mathrm{Nb}$ e Mo no material microligado, como diferença dos outros materiais. Com isso, as diferenças observadas nos ensaios mecânicos, entre o material forjado e fundido, serão consequência dos processos de fabricação. Podendo, assim, classificar qual tipo de processamento fornece à liga melhores propriedades mecânicas, para o caso em estudo.

Tabela 2: Composição química em porcentagem de peso.

\begin{tabular}{c|c|c|c|c|c|c|c|c|c|c}
\hline MATERIAL & $\mathbf{C} \%$ & $\mathbf{M n} \%$ & $\mathbf{P} \%$ & $\mathbf{S} \%$ & $\mathbf{S i} \%$ & $\mathbf{C r} \%$ & $\mathbf{N b} \%$ & $\mathbf{M o} \%$ & $\mathbf{A l} \%$ & $\mathbf{C u} \%$ \\
\hline Especificado & 0,67 & 0,60 & 0,030 & 0,005 & 0,15 & 0,25 & & & \\
AAR M-107 & 0,77 & 0,90 & máx. & 0,040 & 1,00 & máx. & & & máx. & máx. \\
\hline Forjado & 0,712 & 0,806 & 0,016 & 0,013 & 0,272 & 0,179 & ---- & --- & 0,009 & 0,118 \\
\hline Fundido & 0,719 & 0,731 & 0,021 & 0,012 & 0,553 & 0,043 & ---- & --- & 0,009 & 0,022 \\
\hline
\end{tabular}

Os resultados dos ensaios de tração dos materiais estudados são apresentados na Tabela 3.

Tabela 3: Resultados dos ensaios de tração, onde $\boldsymbol{\sigma}_{\mathbf{T}}$ - Tensão máxima de tração; $\boldsymbol{\sigma e}$ - Tensão de escoamento.

\begin{tabular}{l|c|c|c}
\hline MATERIAL & $\boldsymbol{\sigma}_{\mathbf{T}}(\mathrm{MPa})$ & $\boldsymbol{\sigma e}(\mathrm{MPa})$ & ALONGAMENTO (\%) \\
\hline Fundido & $1124,6 \pm 14,9$ & $803,8 \pm 14,6$ & $13,5 \pm 0,3$ \\
\hline Forjado & $1150,7 \pm 3,5$ & $850,9 \pm 4,6$ & $12,9 \pm 0,6$ \\
\hline Microligado & $1185,0 \pm 17,9$ & $954,3 \pm 8,2$ & $13,1 \pm 0,4$ \\
\hline
\end{tabular}

Analisando-se os valores de resistência e escoamento, observa-se que o aço microligado obteve um resultado superior, sem perda de ductilidade quando comparado aos outros materiais. O ganho de resistência sem perda da ductilidade se deve, então, à adição dos elementos de liga $\mathrm{Nb}$ e Mo, visto que estes elementos 
são as principais diferenças em relação a composição química dos outros materiais, conforme Tabela 2.

Os valores encontrados nos ensaios do material Microligado estão de acordo com os trabalhos de $A n$ drade et al (2009) e Villas Bôas et al (2010) onde um aço ferroviário similar ao estudado nesta pesquisa microligado ao $\mathrm{Nb}$ e Mo - apresentou respectivamente os seguintes resultados: $\sigma_{\mathrm{T}}=1263 \mathrm{MPa}, \sigma_{\mathrm{e}}=888 \mathrm{MPa}$ Alongamento $=14 \%$, e $\sigma_{\mathrm{T}}=1219 \mathrm{MPa}, \sigma_{\mathrm{e}}=851 \mathrm{MPa}$, Alongamento $=13 \%$. Para o material Fundido e para o Forjado, como se tratam de materiais fabricados conforme o padrão da Classe "C" (SAE-1070) da norma AAR M-107 (2011) [16] os resultados encontrados estão dentro dos limites estabelecidos e podem ser comparados com os resultados dos trabalhos de Robles Hernándeza et al (2011) [17], $\sigma_{\mathrm{T}}=970 \mathrm{MPa}$ e Alongamento $=16 \%$, e Queiroz et al (2012) [18], $\sigma_{\mathrm{T}}=1192,4 \mathrm{MPa}, \sigma_{\mathrm{e}}=814 \mathrm{MPa}$ e Alongamento $=13 \%$.

As amostras dos aços Fundido, Forjado e Microligado foram atacadas com Nital $2 \%$ e observadas com auxílio de microscopia óptica, as imagens na Figura 6(a) e 6(b) revelam microestruturas predominantemente perlíticas com baixa quantidade de ferrita, visto que os aços estudados possuem o teor de carbono em sua composição próximos ao eutetóide $(0,77 \%$ C). A estrutura composta por perlita é normalmente desejada e especificada pela maioria das normas ferroviárias, inclusive na norma utilizada neste trabalho a AAR M-107 (2011) [16].
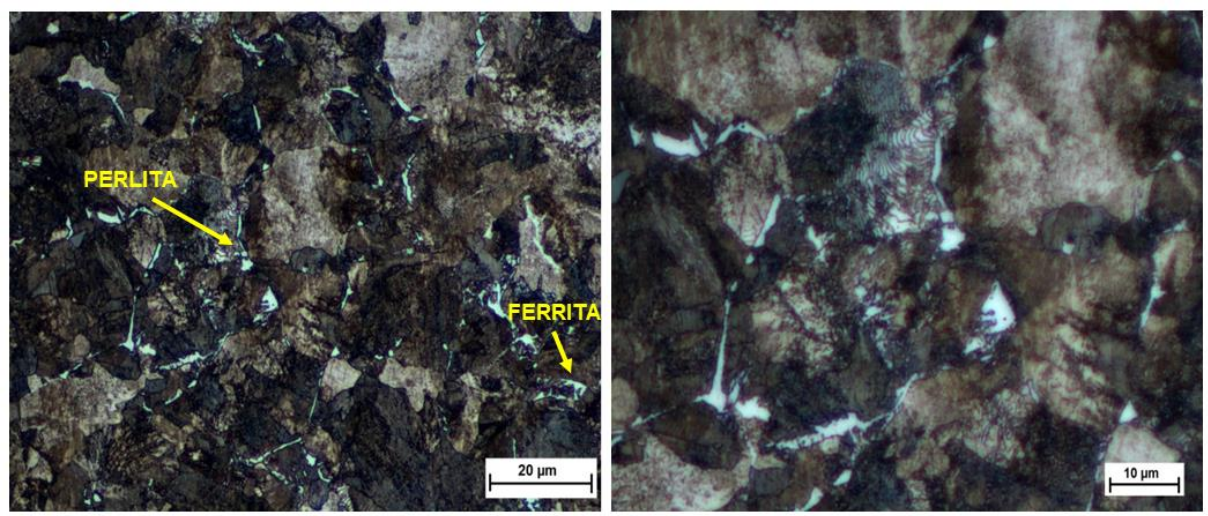

Figura 6: (a) Microestrutura do material Fundido. Ataque com Nital 2\% e observação por Microscopia óptica. (b) Ampliação com detalhes das lamelas de ferrita e cementita na perlita.

Na Figura 6(a) é ilustrada a microestrutura do aço na condição Fundida onde se observa uma microestrutura composta basicamente por perlita fina e pouca quantidade de ferrita nos contornos perlíticos. $\mathrm{Na}$ Figura 6(b) é uma ampliação da Figura 6(a) onde se observa detalhes das lamelas do microconstituinte perlítico. A microestrutura encontrada nesta condição de fabricação é característica deste material e processamento térmico, e está de acordo com o trabalho de Fuoco, Ferreira e Azevedo (2004) [19] e Tarafder, Sivaprasad e Ranganath (2007) [20], onde através de análises em rodas fundidas verificou-se que a microestrutura do material era composta por perlita e ferrita.

Para o material na condição Forjada, a estrutura observada, Figura 7(a) e 7(b), também é predominantemente perlítica, uma vez que a composição química dos materiais Forjado e Fundido são muito próximas e o tratamento térmico é composto pelas mesmas etapas definidas pela norma AAR M-107 (2011) [16]. Parida, Das e Tarafder (2009) [21] e Robles Hernándeza et al (2011) [17] observaram em seus trabalhos a microestrutura do aço classe "C" de rodas ferroviárias forjadas e concluíram que a estrutura composta por perlita é predominante para este material e condição de processamento, sendo observado também pelos autores uma pequena quantidade de ferrita pró-eutetóide no contorno de grão do material. 

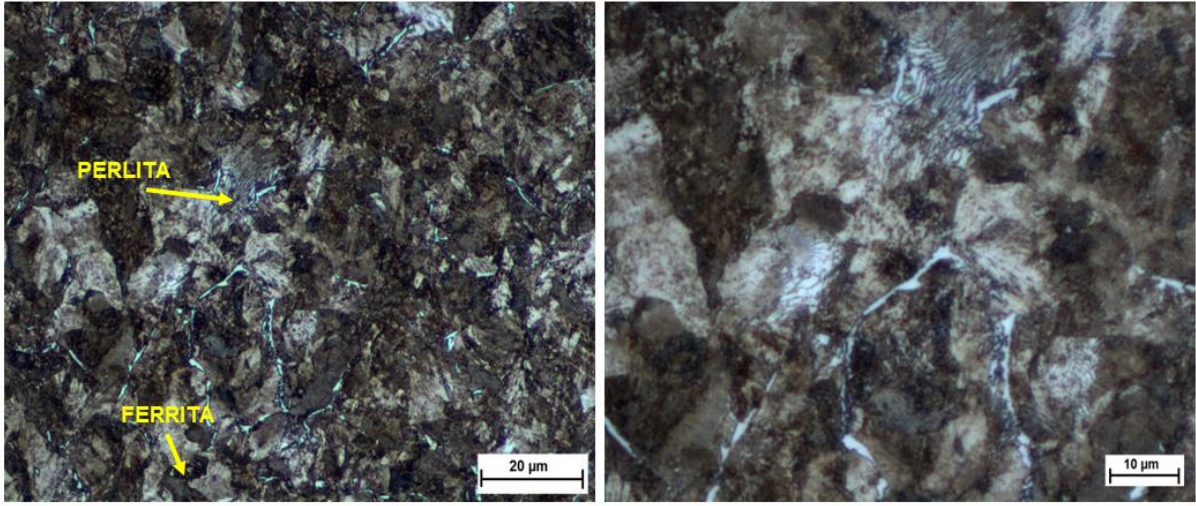

Figura 7: (a) Microestrutura do material Forjado. Ataque com Nital 2\% e observação por Microscopia óptica. (b) Ampliação com detalhes das lamelas de ferrita e cementita na perlita.

A microestrutura observada para o aço forjado e Microligado, Figura 8(a) e 8(b), é composta por perlita e ferrita e está de acordo com o trabalho de Andrade et al (2009) [22], onde o mesmo tipo de aço microligado apresenta uma estrutura perlítica com pequenas frações de ferrita. Nota-se, contudo, o aumento do volume de ferrita nesse material em relação aos aços Fundido e Forjado, ambos sem microadição de elementos de liga, isto pode ser consequência da ação do molibdênio que favorece a formação dessa fase (IMOA, 2013 [23]) e consequentemente gera um aumento na tenacidade do material.
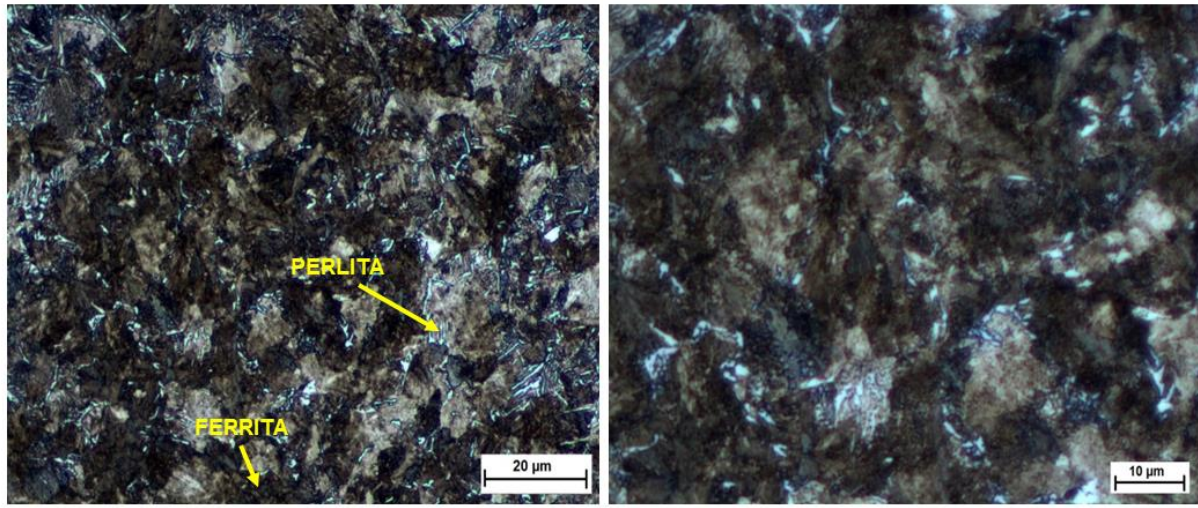

Figura 8: (a) Microestrutura do material Microligado. Ataque com Nital 2\% e observação por Microscopia óptica. (b) Ampliação com detalhes das lamelas de ferrita e cementita na perlita.

Os ensaios de tenacidade à fratura foram realizados em quatro corpos de prova do tipo "CT" para cada condição de material estudado. Os resultados dos ensaios são mostrados na Tabela 4. O cálculo de "K ${ }_{C}$ " foi feito conforme a Equação 2, sendo o tamanho da trinca utilizado na função $f(a / W)$, uma média de cinco medidas feitas na face da superfície da fratura.

Tabela 4: Comparativo dos resultados dos ensaios de Tenacidade à Fratura.

\begin{tabular}{c|c}
\hline MATERIAL & $\mathbf{K}_{\mathbf{C}}\left(\mathbf{M P a}^{\mathbf{1 / 2}}\right)$ \\
\hline Fundido & $43,4 \pm 1,2$ \\
\hline Forjado & $49,4 \pm 2,8$ \\
\hline Microligado & $55,4 \pm 1,4$ \\
\hline
\end{tabular}

Na Figura 9 é mostrado graficamente os resultados e o comparativo dos valores de " $K_{C}$ " das condições ensaiadas. Para o material microligado o resultado encontrado é aproximado ao da pesquisa de Villas Bôas (2010) [24], $\mathrm{K}_{\mathrm{C}}=51 \mathrm{MPa} \cdot \mathrm{m}^{1 / 2}$. Em estudo comparativo com rodas fundidas e forjadas, Tarafder et al 
(2007) e Sivaprasad et al (2007) [20], observaram comportamento superior das rodas forjadas em relação as fundidas ao analisar os valores obtidos em ensaios de tenacidade à fratura para os dois tipos de rodas. Segundo Minicucci, Milagres e Villas Bôas (2010) [25] o valor encontrado de tenacidade à fratura para o material Classe "C" forjado é na faixa de $46 \mathrm{MPa} . \mathrm{m}^{1 / 2}$, já para o mesmo material fabricado pelo processo de fundição, Queiroz (2012) [18] encontrou valores na faixa de 43,2 MPa.m ${ }^{1 / 2}$.

TENACIDADE A FRATURA

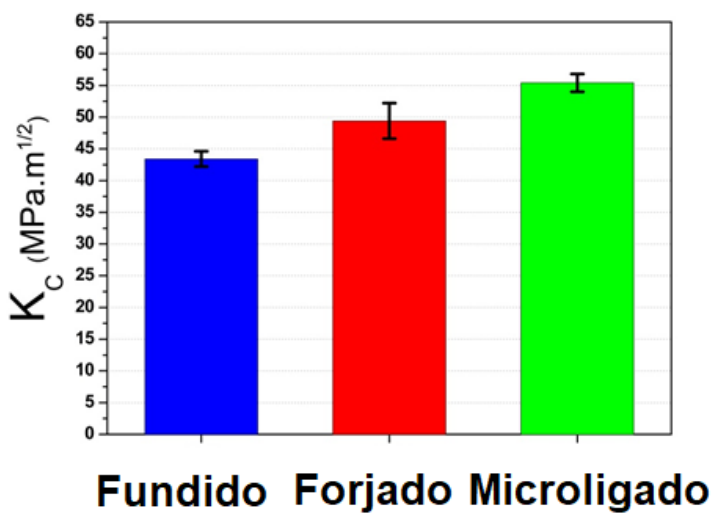

Figura 9: (a) Microestrutura do material Microligado. Ataque com Nital 2\% e observação por Microscopia óptica. (b) Ampliação com detalhes das lamelas de ferrita e cementita na perlita.

Analisando-se os resultados do ensaio de tenacidade à fratura para as amostras em estudo, observa-se que este ensaio é sensível a aspectos microestruturais, como defeitos internos, e mesmo tendo o material fabricado pelo processo de fundição sob pressão uma qualidade interna superior comparado a processos de fundição convencionais, o aparecimento de microvazios é inerente a este tipo de processamento, o que fragiliza o aço e possui grande influência no surgimento de trincas por fadiga. Consequentemente, o valor de " $\mathrm{K}_{\mathrm{C}}$ " deste material é inferior quando comparado ao mesmo aço (Classe "C") fabricado pelo processo de forjamento.

O forjamento garante uma estrutura mais refinada e diminui a probabilidade de microdefeitos internos, aumentando assim, a tenacidade e a resistência ao aparecimento de trincas (PESSARD et al, 2011) [26]. O aço microligado foi fabricado por forjamento e sofreu um processo de desgaseificação à vácuo durante sua produção, o que confere ao mesmo um menor nível de hidrogênio e consequentemente uma melhora em suas propriedades mecânicas como tenacidade à fratura e fadiga (ROBLES HERNÁNDEZA et al, 2011; MINICUCCI, 2011) [17,25]. Lonsdate, Dedmon e Pilch (2005) [27] observaram em sua pesquisa um aumento de aproximadamente $23 \%$ no valor de tenacidade à fratura de um aço microligado Classe "C" quando comparado ao mesmo aço sem adição de elementos de liga. Nas análises das micrografias, Figura 8(a) e 8(b), observou-se uma diminuição no tamanho de grão austenítico devido à microadição de Nióbio e Molibdênio, o que segundo Das et al (2006) [28] e Murakami (2012) [29] aumenta a tenacidade à fratura do material já que quanto menor o tamanho de grão maior a dificuldade do defeito (trinca) se propagar.

A Figura 10 ilustra o comparativo das curvas $S x N$ dos aços estudados e permite observar que o material na condição fundida tem um comportamento em fadiga inferior quando comparado aos demais materiais testados. A resistência à fadiga superior de materiais ferroviários forjados comparados com materiais fundidos foi observada por Queiroz (2012) [18] em sua pesquisa, através de ensaios de fadiga realizados por flexão em três pontos. 


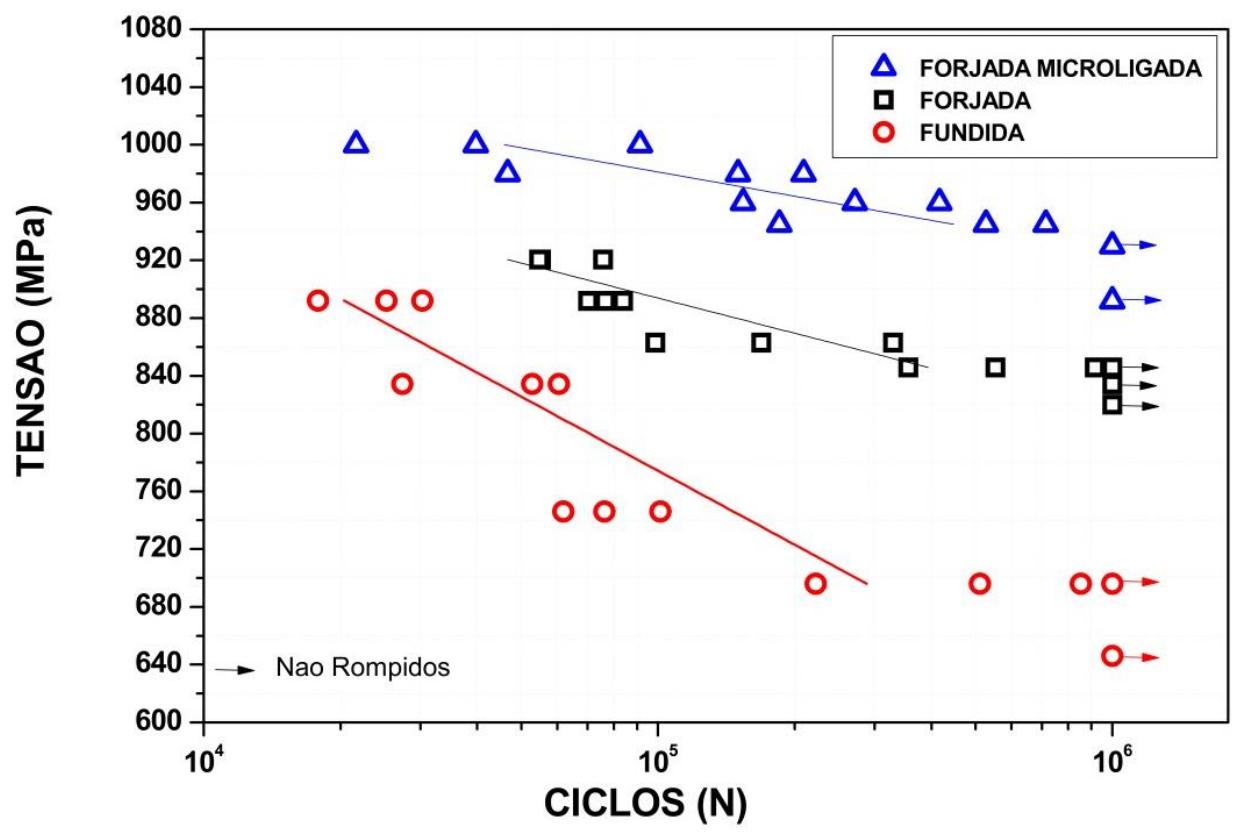

Figura 10: Comparativo das curvas de fadiga dos materiais Forjado, Fundido e Microligado.

Analisando-se os resultados do ensaio de fadiga é possível verificar que o material Microligado apresenta uma melhor vida em fadiga, sendo seguido pelo material Forjado quando comparados com o material Fundido. Tal melhora pode ser visualizada através do comparativo das curvas " $\sigma x N$ " e no valor de vida infinita determinado em $10^{6}$ ciclos, que para o material Classe "C" - Forjado foi de aproximadamente 834 $\mathrm{MPa}$, no material Classe "C" - Fundido foi de $646 \mathrm{MPa}$ e para o Microligado de $930 \mathrm{MPa}$.

Esta superioridade do aço microligado ao Nióbio e Molibdênio se deve à redução do tamanho de grão austenítico, conforme micrografia mostrada na Figura 8, o que aumenta a resistência à fadiga do aço. A diminuição do tamanho de grão austenítico é atribuída ao efeito do nióbio em solução sólida de retardar a recristalização da austenita após o forjamento e também ao efeito dos carbonitretos de nióbio e molibdênio precipitados na austenita que restringem o crescimento dos grãos (VILLAS BOAS, 2010 [24]).

O processamento de materiais obtidos por forjamento propicia uma menor quantidade de defeitos internos comparados aos fundidos, o que interfere diretamente nas propriedades de tenacidade e fadiga. Os defeitos internos tais como vazios e microinclusões funcionam como concentradores de tensão e consequentemente locais propícios para a nucleação de trincas por fadiga. A análise da superfície de fratura dos corpos de prova de fadiga revelaram o início da propagação da fadiga em defeitos internos no material fundido, conforme Figura 11. Tal característica foi observada em diversos espécimes analisados nesta condição de fabricação. Já na análise feita nos corpos de prova do material forjado e do Microligado, Figuras 12 e 13, esta característica não foi encontrada em nenhuma situação, sendo o início da trinca de fadiga sempre proveniente da superfície do corpo de prova, região de maior concentração de tensão e de maior probabilidade de início de trincas por fadiga pelo fenômeno das bandas de deslizamento. 


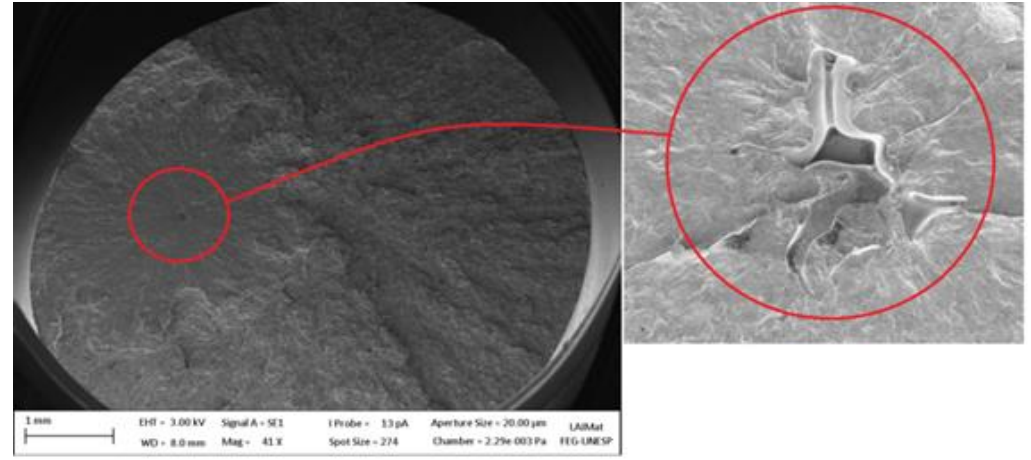

Figura 11: Análise da superfície de fratura do corpo de prova de fadiga (Material Fundido) - MeV.
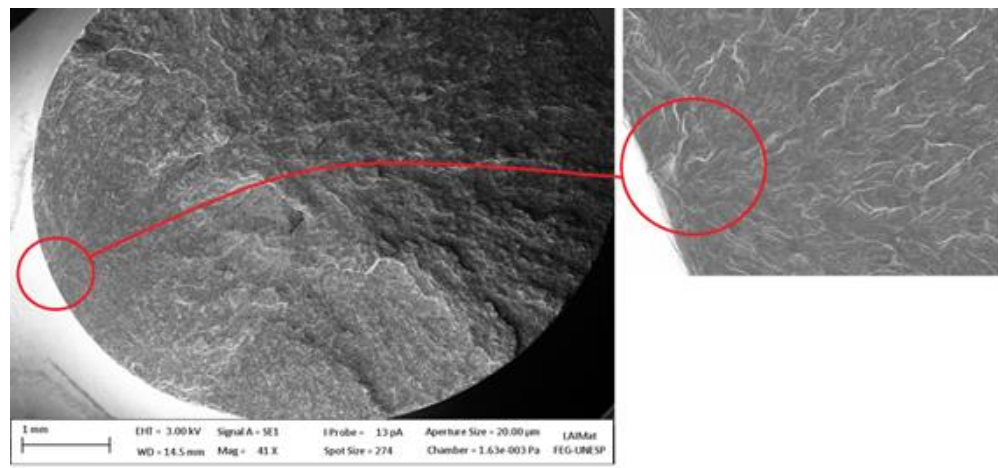

Figura 12: Análise da superfície de fratura do corpo de prova de fadiga (Material Forjado) - MeV.
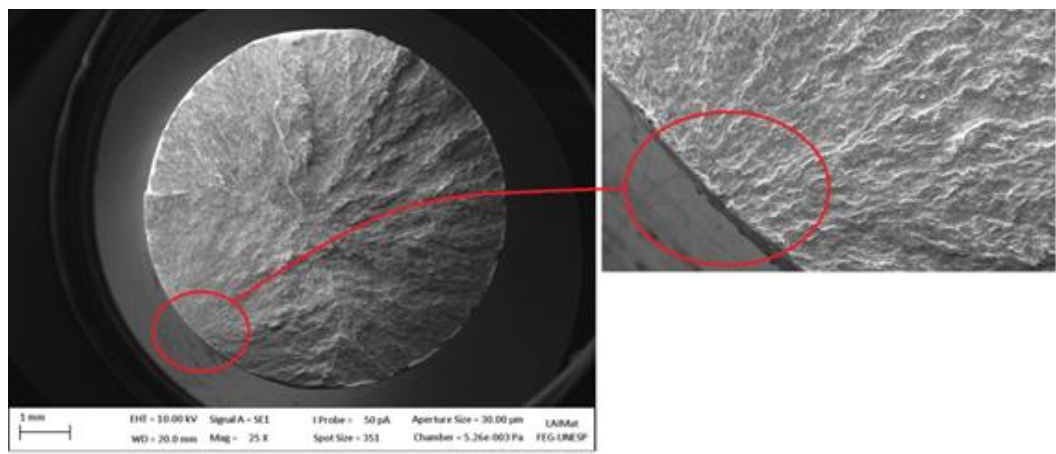

Figura 13: Análise da superfície de fratura do corpo de prova de fadiga (Material Forjado) - MeV.

\section{CONCLUSÕES}

Analisando-se os resultados obtidos foi possível verificar que:

- A microadição de Nióbio e Molibdênio no aço utilizado para fabricação de rodas ferroviárias, melhorou as propriedades de tenacidade e de resistência à fadiga da liga em estudo;

- Os resultados obtidos para o material Fundido mostraram que a microestrutura e as propriedades de tração são equivalentes quando comparadas com os demais materiais estudados. Porém, nos ensaios mais sensíveis a aspectos microestruturais, como defeitos e vazios, verificou-se propriedades inferiores comparadas com os materiais forjados em estudo;

- Os valores de tenacidade à fratura demonstram que o material fundido em estudo tem um comportamento mais frágil que os forjados. Tal característica é comprovada nos ensaios de fadiga, onde seu o comportamento foi consideravelmente inferior aos materiais forjados, sendo possível concluir que devido ao maior número de defeitos internos, que funcionam como concentradores de tensão, seu comportamento em fadiga, bem como o limite de resistência à 
fadiga (vida infinita), são inferiores no comparativo com os materiais forjados estudados neste trabalho.

\section{AGRADECIMENTOS}

À Capes, IFSP, UNESP e MWL Brasil.

\section{BIBLIOGRAFIA}

[1] SOARES, H., et al., "Fatigue life of a railway wheel under uniaxial and multiaxial loadings", Procedia Structural Integrity, v. 13, pp. 1786 - 1791, 2018.

[2] ZUCARELLI, T., et al., "Experimental characterization of the mechanical properties of railway wheels manufactured using class C material”, Theoretical and Applied Fracture Mechanics, v. 85, pp. 134-139, 2016.

[3] UNITED STATES DEPARTMENT OF TRANSPORTATION. Bureau of Transportation Statistcs. Disponível em <https://www.bts.gov/content/train-fatalities-injuries-and-accidents-type-accidenta>. Acesso em 15 de Agosto de 2019.

[4] STRÁŽOVEC, P., et al., "Detection of residual stress in a railway wheel", Tranportation Research Procedia, v. 40, pp. 898 - 905, 2019.

[5] ZHANG, M.R., GU, H.C. "Fracture toughness of nanostructured railway wheels", Engineering Fracture Mechanics, v.75, pp. 5113-5121, 2008.

[6] HUANGA, X., et al., "Experimental characterization of the mechanical properties of railway wheels manufactured using class C material", Engineering Failure Analysis, v. 97, pp. 718 - 726, 2019.

[7] CHONGFEI ZHU, C., et al., "Failure mechanism analysis on railway wheel shaft of power Locomotive", Engineering Failure Analysis, v. 104, pp. 25 - 38, 2019.

[8] ASSOCIATION OF AMERICAN RAILROAD. AAR M-107: Railway Wheels - Manual of Standards and Recommended Practices - Section G. Washington, 2011.

[9] ELWAZRI, A. M., WANJARA, P., YUE, S. "The effect of microstructural characteristics of pearlite on the mechanical properties of hypereutectoid steel", Materials Science and Engineering: A, v. 404, n. 1-2, pp. 91-98, 2005.

[10] ZENG, D., et al., "Optimization of strength and toughness of railway wheel steel by alloy design", Materials \& Design, v. 92, pp. 998-1006, 2016.

[11] AMERICAN SOCIETY FOR TESTING AND MATERIALS. ASTM E8/E8M: Standard Test Methods for Tension Testing of Metallic Materials, Philadelphia, 2016.

[12] AMERICAN SOCIETY FOR TESTING AND MATERIALS. ASTM E3-11: Standard Guide for Preparation of Metallographic Specimens, 2017.

[13] AMERICAN SOCIETY FOR TESTING AND MATERIALS. ASTM E23: Standard Test Methods for Notched Bar Impact Testing of Metallic Materials, 2018.

[14] AMERICAN SOCIETY FOR TESTING AND MATERIALS. ASTM E-399: Standard Test Method for Linear-Elastic Plane-Strain Fracture Toughness KIc of Metallic Materials., Philadelphia, 2019.

[15] AMERICAN SOCIETY FOR TESTING AND MATERIALS. ASTM E-466: Standard Practice for Conducting Force Controlled Constant Amplitude Axial Fatigue Tests of Metallic Materials. Pennsylvania, 2015.

[16] ASSOCIATION OF AMERICAN RAILROAD. AAR M-107: Railway Wheels - Manual of Standards and Recommended Practices - Section G. Washington, 2011.

[17] ROBLES HERNÁNDEZ., et al., "Properties and microstructure of high performance wheels", Wear, v. 271, n. 1-2, p. 374-381, 2011.

[18] QUEIROZ, S. R. S. "Propriedades mecânicas e micromecanismos de fratura de corpos-de-prova usinados de rodas ferroviárias fundidas e forjadas", Tese de Doutorado, Faculdade de Engenharia Mecânica, Universidade Estadual de Campinas, Campinas, 2012.

[19] FUOCO, R., FERREIRA, M. M., AZEVEDO, C. R. F. "Failure analysis of a cast steel railway wheel", Engineering Failure Analysis, v. 11, n. 6, pp. 817-828, 2004. 
[20] TARAFDER, S., SIVAPRASAD, S., RANGANATH, V. R. "Comparative assessment of fatigue and fracture behaviour of cast and forged railway wheels", Fatigue \& Fracture of Engineering Materials and Structures, v. 30, n. 9, pp. 863-876, 2007.

[21] PARIDA, N., DAS, S. K., TARAFDER, S. "Failure analysis of railroad wheels", Engineering Failure Analysis, v. 16, n. 5, pp. 1454-1460, 2009.

[22] ANDRADE, A. P., VILlAS BÔAS, R. L., PIVOTTO, D. J. R., et al., "Efeito da adição de molibdênio e nióbio em aços com carbono entre 0,5 e 0,7 \%", In: Anais do $5^{\circ}$ Congresso Brasileiro de Engenharia de Fabricação, Belo Horizonte, MG, 14 a 17 de Abril de 2009, pp 1-8, 2009.

[23]INTERNATIONAL MOLYBDENUM ASSOCIATION (IMOA). Disponível em: <http://www.imoa.info/molybdenum_uses/moly_grade_alloy_steels_irons/metallurgy_alloy_steel_iron.php>. Acesso em 08/2019.

[24] VILLAS BÔAS, R. L. "Desenvolvimento de aço microligado para rodas ferroviárias", Dissertação de Mestrado, Faculdade de Engenharia Mecânica, Universidade Estadual de Campinas, Campinas, 2010.

[25] MINICUCCI, D. J., MILAGRES, M. R., VILLAS BÔAS, R. L. "Fracture toughness test in railroad wheels", In: Proc. of 16th International Wheelset Congress, Cidade do Cabo, África do Sul, pp. 01-10, 2010.

[26] PESSARD, E., MOREL, F., MOREL, A., et al., "Modelling the role of non-metallic inclusions on the anisotropic fatigue behaviour of forged steel", International Journal of Fatigue, v. 33, n. 4, pp. 568-577, 2011.

[27] LONSDATE, C., DEDMON, S., PILCH, J. "Recent developments in forged railroad wheels for improved performance", Joint Rail Conference, Anais, pp.39-43. Pueblo, Colorado, 2005.

[28] DAS, S.K., SIVAPRASAD, S., DAS, S., et al., "The effect of variation of microstructure on fracture mechanics parameters of HSLA-100 steel", Material Science \& Engineering A, v.431, n. 1-2, pp.68-79, Sept. 2006.

[29] MURAKAMI, Y. "Materials defects as the basis of fatigue design", International Journal of Fatigue, v. 41, n. 2012, pp. 2-10, 2012.

\section{ORCID}

Luiz Gustavo de Oliveira Antonio dos Reis de Faria Neto Cristina Sayuri Fukugauchi Valdir Alves Guimarães https://orcid.org/0000-0002-1907-0725

https://orcid.org/0000-0003-3910-7625

https://orcid.org/0000-0001-9643-9912

https://orcid.org/0000-0002-8954-245X 